\title{
Comunicación y proceso revolucionario en El Salvador. La prensa clandestina en la configuración y desarrollo de las organizaciones insurgentes (1970-1980)'
}

\author{
Eudald Cortina Orero \\ Universidad de Santiago de Compostela \\ endald.cortina@usc.es
}

RESUMEN: Desde comienzos de la década de 1970, diferentes organizaciones político-militares, como las Fuerzas Populares de Liberación (FPL) y el Ejército Revolucionario del Pueblo (ERP), se irían conformando en El Salvador, fruto tanto de divergencias en el seno del Partido Comunista (PCS) como de la radicalización de amplias franjas de la juventud salvadoreña. Este trabajo aborda el rol desarrollado en este proceso por la prensa clandestina como una herramienta de consolidación orgánica y homogeneización de la militancia de estas organizaciones emergentes. Publicaciones que no sólo marcarían pautas de acción sino que irían configurando un nuevo universo militante que girará en torno a la lucha armada, con sus propios símbolos y códigos, y mediante el que las organizaciones insurgentes buscarán, en primer lugar, diferenciarse y, posteriormente, convertirse en alternativa respecto a los proyectos políticos de la izquierda legal o electoral.

ABSTRACT: Since the early 1970's various political-military organizations such as the Popular Liberation Forces (FPL) and the People's Revolutionary Army (ERP) would be forming in El Salvador, as the result of differences within the Communist Party (PCS) and the radicalization of large segments of Salvadoran youth. This paper addresses the role developed in this process by the underground press as a tool for organizational consolidation and homogenization of the militancy of these emerging organizations. Publications that would mark not only action guidelines but would set up a new militant universe that will focus on armed struggle, with its own symbols and codes. This would allow the insurgent organizations to seek, first, differentiate and later become an alternative political project in opposition to the legal or electoral left.

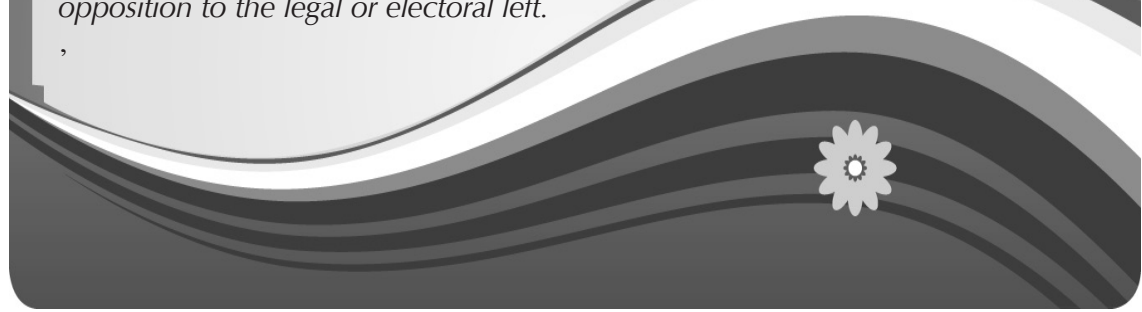




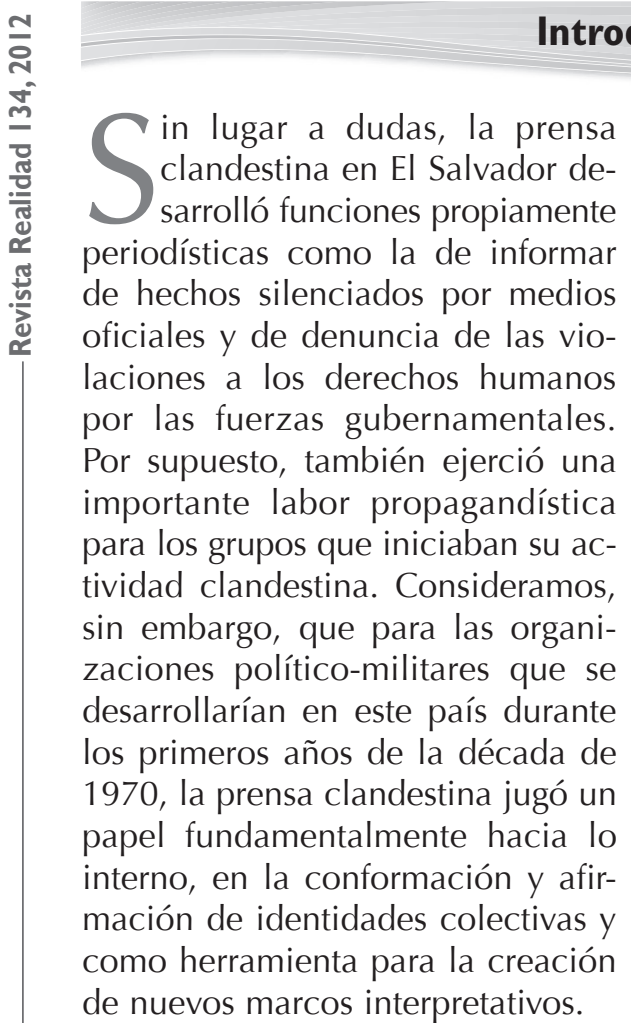

En este sentido, la prensa clandestina actuó para estos grupos emergentes como una herramienta de consolidación orgánica y homogeneización de la militancia, configurando un universo militante que tendrá su eje en torno a la lucha armada. Estos órganos clandestinos ejercerán también un papel clave como orientadores para la acción colectiva, como soporte para el debate con otros movimientos y como un instrumento para el crecimiento de la organización, no sólo como herramienta para el reclutamiento, sino como un medio para la inserción de estas organizaciones en nuevos ámbitos sociales y la apertura de trabajo político hacia nuevos actores sociales.

A lo largo de este artículo, profundizaremos en estos aspectos, centrándonos en los procesos identitarios y homogeneizadores al interior de las organizaciones político-militares salvadoreñas y en el uso de la prensa clandestina como herramienta para la construcción y desarrollo orgánico de éstas. Para ello, utilizaremos como marco interpretativo los aportes de teóricos de los movimientos sociales y de historiadores de la comunicación, que han abordado el fenómeno de la prensa clandestina en diferentes latitudes. Metodológicamente, partiremos de un análisis de contenido de las publicaciones centrales de las Fuerzas Populares de Liberación "Farabundo Martí" (FPL) - El Rebelde y Estrella Roja- y del Ejército Revolucionario del Pueblo (ERP) - El Combatiente, Por la Causa Proletaria y Prensa Comunista, que abarca, en lo posible, desde el surgimiento de estas publicaciones, a finales de 1971, hasta el cierre de esta década, cuando estas organizaciones desarrollen esfuerzos unitarios, que finalmente tendrán su reflejo en la constitución del Frente Farabundo Martí para la Liberación Nacional (FMLN).

El grueso de las fuentes documentales utilizadas en este trabajo 
procede del Centro de Información, Documentación y Apoyo a la Investigación (CIDAI) de la Universidad Centroamericana "José Simeón Cañas" (UCA), aunque también se han incorporado fuentes procedentes de los archivos salvadoreños Fundabril, el Museo de la Palabra y la Imagen (MUPI), y del International Institute of Social History (IISH), con sede en Ámsterdam.

Por otro lado, nos apoyaremos en fuentes orales, producto de en- trevistas a dirigentes y responsables de las estructuras de comunicación de las organizaciones insurgentes, desarrolladas durante una estancia de investigación en El Salvador, entre octubre y noviembre de 2011. Utilizaremos también entrevistas realizadas por otros investigadores $y$, especialmente, los diferentes trabajos memorialísticos desarrollados por exmilitantes de las estructuras clandestinas objeto de estudio, FPL y ERP.

\section{Comunicación y proceso revolucionario en El Salvador}

Las organizaciones políticomilitares que insurgieron en $\mathrm{El}$ Salvador a comienzos de la década de 1970 desarrollaron diversas estrategias comunicativas y pusieron en marcha diferentes medios informativos con los que buscaron dar conocer sus propuestas políticas y publicitar y enmarcar sus acciones armadas. Así, tras un periodo de clandestinidad estricta, que abarcó desde la conformación de estas organizaciones hasta la reivindicación de sus primeras acciones armadas, tanto el ERP como las FPL comenzarán a desplegar estrategias con las que dar visibilidad a sus organizaciones y a sus objetivos. Dentro de esta actividad, podemos enmarcar la toma de radios, los secuestros de contenido político, el desarrollo de diferentes acciones de propaganda armada $y$, conforme avance el conflicto, las incursiones guerrilleras y la toma de poblaciones.
Paralelamente a estos esfuerzos propagandísticos, las organizaciones guerrilleras pondrán en marcha diferentes herramientas comunicativas durante el desarrollo del conflicto - prensa clandestina, radios guerrilleras $^{2}$, agencias informativas en el exterior $^{3}$, producciones audiovisuales y hasta algunos iniciales coqueteos con la comunicación digital, en la etapa final de la guerra-. Cada uno de estos medios adquirirá un mayor o menor peso en la estrategia comunicativa de las organizaciones, atendiendo a la coyuntura y la agudización del conflicto. Así, mientras que en buena parte de la década de 1970 la prensa clandestina será prácticamente el único medio informativo tanto de las organizaciones político-militares como de los movimientos sociales, ésta, sin llegar a extinguirse, perderá presencia en favor de otros medios durante la siguiente década. 
Diversos factores incidirán en este proceso. En primer lugar, la propia dinámica del conflicto obligará a las organizaciones a centrar sus recursos humanos y técnicos en función de la guerra, generando infraestructuras y logística para los frentes de guerra y derivando los esfuerzos propagandísticos al ámbito internacional, en búsqueda del reconocimiento como fuerza beligerante y buscando canalizar la solidaridad internacional. Intervendrían, también, diversos factores de contenido organizativo. El sostenimiento en la clandestinidad de un aparato de propaganda -incluyendo equipos humanos, talleres de impresión y redes de distribución-, absorbía grandes recursos económicos y humanos cuando, como venimos señalando, los esfuerzos de estas organizaciones se reorientaban al impulso militar del conflicto. La prensa clandestina venía mostrando, además, signos de agotamiento y cierta ineficacia - especialmente entre la población no organizada - en un contexto de aguda represión gubernamental, donde la sola tenencia de un periódico clandestino podía significar el asesinato para su portador, o su encarcelamiento en el mejor de los casos. El desarrollo de los frentes de guerra y la progresiva ruralización del conflicto limitarían aún más la utilidad de la prensa clandestina como instrumento organizador $y$ adoctrinador, ante los elevados índices de analfabetismo en este ámbito social. En este contexto y pese a sus condicionamientos técnicos iniciales, una herramienta como la radio ${ }^{4}$, en especial la emisora Radio Venceremos, pasará a convertirse en el eje central de la política comunicativa del FMLN y en un factor estratégico en el desarrollo de la guerra, tanto por su eficiencia e inmediatez, como por su capacidad de vincular en forma más directa a las élites revolucionarias _la comandancia del FMLN-con una amplitud de públicos organizados y no organizados.

Por último, aunque este aspecto parece tener menor impacto que los anteriores en la evolución de la prensa clandestina, la conformación de un frente político y militar (FMLN) y su correlato en proyectos comunicativos si no unitarios al menos compartidos, relativizará la necesidad de sostener órganos partidarios que, si bien con mucha menor incidencia que en la década de 1970, continuarán existiendo hasta el final del conflicto.

\section{El surgimiento de la prensa clandestina}

Tanto el ERP como las FPL se darán a conocer a la opinión pública salvadoreña con sendas acciones armadas, tras una etapa inicial de trabajo político hacia lo interno y de una actividad militar preparatoria. El ERP, que venía estructurándose desde inicios de 
1970 producto de la convergencia de al menos tres núcleos de activistas procedentes del movimiento estudianti ${ }^{5}$, vería la luz pública con una recuperación de armas el 2 de marzo de $1972^{6}$. Las FPL, fundadas el 1 de abril de 1970 con militantes procedentes del Partido Comunista de El Salvador (PCS), se darían a conocer meses después, mediante un ataque explosivo, en agosto de 1972, contra la embajada argentina en San Salvador, en represalia por la masacre de Trelew.

Desde finales de 1971, antes incluso de su puesta en escena, el ERP comenzó a editar El Combatiente, como una publicación teórica e ideológica, inicialmente con un perfil "exclusivo" e "interno"7, que en sus primeros números incidió en la construcción del aparato armado y en la actividad militar como eje central en la estrategia y desarroIlo del ERP ${ }^{8}$. Siguió publicándose, primero como órgano divulgativo del ERP y después como revista política-ideológica del Partido de la Revolución Salvadoreña $(\mathrm{PRS})^{9}$, al menos hasta finales de 1980. En este camino, la publicación perdería progresivamente su carácter fundamentalmente doctrinario y teórico y ampliaría su público potencial, para convertirse en un soporte que proyectara las acciones armadas del ERP y las líneas de acción coyunturales propuestas por la organización.
Un año después de que comenzara a publicarse El Combatiente, el ERP impulsaría la edición del periódico Por la causa proletaria, cuyo primer número aparecería en octubre de $1972^{10}$. La creación de esta cabecera respondió a un proceso de fuerte cuestionamiento interno sobre las limitaciones del desarrollo estrictamente militar y a la desconexión con el movimiento de masas, que en ese momento percibía parte de la dirección del ERP. Fruto de este cuestionamiento y con el objetivo de revertir estas tendencias y lograr insertarse en el movimiento obrero, esta organización impulsaría la línea política denominada "Resistencia Nacional". Por la causa proletaria surgiría adscrito a esta línea de trabajo y destinado teóricamente a las bases de la organización y al movimiento obrero. Eduardo Sancho, sin embargo, matiza este aspecto y señala que no se trataba de un periódico masivo, sino enfocado a los dirigentes sindicales, para que éstos aplicaran la línea política en sus federaciones.

Cuando más tarde se produzca la ruptura en el ERP y diversas estructuras y grupos de militantes conformen la organización Resistencia Nacional (RN), Por la causa proletaria pasará a convertirse en el órgano partidario de la RN:

"Reeditamos Por la Causa Proletaria, pero queda en forma más interna. Aquí ya ocupa el papel de El Combatiente, 
que era interno, digamos del núcleo élite. Y aquí queda así porque ya ellos (el movimiento social) tienen sus redes sectoriales. Entonces ahí está jugando (otro papel), es el órgano central, el que da las grandes líneas". ${ }^{11}$

El proceso de ruptura tendría también su impacto en las publicaciones del sector que mantendría las siglas del ERP. Así, en mayo de 1975, aparecería el primer número de Prensa Comunista, que tomaría el relevo de El Combatiente como publicación doctrinaria del PRS-ERP. En un contexto de reciente crisis interna derivada del asesinato de Roque Dalton y la separación de la Resistencia Nacional, el objetivo fundamental de Prensa Comunista sería dotar a la organización de una coherencia ideológica en un contexto de lucha fraticida, donde los hasta ese momento compañeros pasaban a ser combatidos:

"El Partido de la Revolución Salvadoreña (PRS) en formación se enfrenta a un periodo crítico de la lucha de clases en el país en donde es necesario implantar una correcta conducción política que disputa a las tendencias desviadas la hegemonía en el movimiento popular, como garantía de que esta situación sea resuelta a favor de la revolución, se plantea como una de sus tareas centrales la lucha ideológica contra el revisionismo de derecha y el reformismo burgués. Nuestro periódico central PRENSA COMUNISTA es el instrumento básico de esta lucha". (Prensa Comunista $\left.N^{\circ} 1, p .3\right)$

Contemporáneo a Por la causa proletaria es el surgimiento de El Rebelde, que se convertiría en el órgano central de las FPL hasta su desaparición. El Rebelde vería la luz dos meses después -en octubre de 1972- de que las FPL hicieran pública su existencia ${ }^{12}$, con una tirada de un centenar de ejemplares, que se iría incrementando durante la década hasta alcanzar un tiraje máximo cercano a los 20.000 ejemplares mensuales ${ }^{13}$. Será el periódico clandestino con mayor regularidad de publicación de los cinco medios analizados y el que mayor proyección alcanzaría, llegando a publicarse una edición internacional del mismo, en 1978, e iniciando una segunda etapa, en octubre de 1983, de incierto recorrido ${ }^{14}$.

Como reflejan sus cifras de tirada, El Rebelde pretendía, pese a sus características de clandestinidad, alcanzar cierta masividad, planteándose como objetivo inicial "elevar la conciencia revolucionaria de las masas avanzadas del pueblo"15. El periódico asumiría durante la dé- 
cada diferentes funciones, entre las que se destacaban para las propias FPL las de "orientador político, propagandístico, agitador" y "organizador para incorporar al pueblo a la guerra prolongada y revolucionaria"16. $^{\prime 16}$. El Rebelde desarrollaría esta labor con el apoyo de toda una red de prensa sectorial, aspecto que tratamos más adelante.

La prensa política clandestina que comenzaría a proliferar en $\mathrm{El}$ Salvador a comienzos de la década de 1970 tenía sus antecedentes en las publicaciones de carácter clandestino y semiclandestino editadas por el Partido Comunista de El Salvador (PCS). Algunas de las nuevas publicaciones buscarían establecer una continuidad con las anteriores recuperando estas cabeceras históricas. Es el caso de la revista teórica de las FPL, Estrella Roja ${ }^{17}$, que recogía el nombre del periódico marxista dirigido por Alfonso Luna y Mario Zapata en el contexto de la insurrección obrero-campesina de $1932^{18}$. La elección de esta cabecera no puede desligarse, como resulta evidente, de la procedencia comunista de los primeros dirigentes de las FPL, pero también cabe enmarcarla en la disputa ideológica que las FPL sostendrán con el PCS y como una reivindicación del pasado combativo de los comunistas salvadoreños, al que las FPL pretendían dar continuidad.

Con una publicación extremadamente irregular -durante la década de 1970 sólo aparecerían cinco números, aunque se reeditarían en forma periódica-, Estrella Roja tenía un carácter marcadamente interno y entre sus contenidos, además del aspecto doctrinario, quedó reflejada la vida interna del partido -reuniones de dirección, congresos, etc.-Aunque fue concebido como una herramienta para la formación de miembros y colaboradores de las $\mathrm{FPL}$, su circulación se limitaría en la práctica a cuadros de dirección y cuadros medios. De hecho, a diferencia de El Rebelde, dependiente de las estructuras de propaganda, la edición de Estrella Roja recaería principalmente en la Comisión Nacional de Educación ${ }^{19}$.

\section{Funciones de la prensa clandestina}

Pedro Ibarra ${ }^{20}$, que retoma el análisis funcional de la prensa clandestina elaborado por Lluís Bassets y Enric Bastardes ${ }^{21}$, señala una serie de funciones generales que desempeña este tipo de comunicación. Entre ellas, destaca su función informativa en tres niveles: informativa directa, contra la falta de información en la prensa legal; informativa esclarecedora, rompiendo el cerco de la "verdad oficial"; e informativa amplificadora, haciéndose eco de conflictos sociales y políticos ausentes en los medios convencionales. A esta función estrictamente periodís- 
tica, Ibarra añade como característica general de la prensa clandestina su vocación doctrinal. Tarea que no se limitará a la difusión de marcos teóricos generales y objetivos y programas políticos, sino que tendrá su continuidad mediante el debate con otros grupos y en una dimensión interna: la propia organización como problema político.

Junto a estos aspectos informativos y doctrinales existiría, para este autor, otras dos funciones centrales en el desarrollo de la prensa clandestina: una función agitativosolidaria -que, para nosotros, refleja la vocación movilizadora presente en cualquier prensa política-; y una función organizativo-militante, que refiere al rol que la prensa clandestina ejerció como instrumento de cohesión del grupo, su papel en la formación y dinámica de la propia militancia, y su dimensión organizativa allí donde las estructuras partidarias no podían llegar —en ámbitos geográficos donde la organización no tenía presencia o esta era poco estable en el tiempo.

Durante la década que va desde la aparición de los periódicos clandestinos en El Salvador hasta la creación de los primeros organismos unitarios de las organizaciones político-militares salvadoreñas (1970-1980), la prensa clandestina cumplirá una serie de funciones tanto hacia el interior de las organizaciones como en relación a lo externo, desde la población no or- ganizada hasta el mismo oponente político y militar. Ciertamente cada una de estas publicaciones incidirá de forma diferente atendiendo a sus características, el público o colectivo al que se dirige y al papel que las propias organizaciones les confirieron en cada momento.

Partiendo de la categorización sobre la funcionalidad de la prensa clandestina planteada por Pedro Ibarra, hemos realizado un análisis de contenido de las publicaciones centrales de las FPL y el ERP en este periodo, con el objetivo de definir cuáles de estas categorías adquirieron mayor peso en sus páginas (Ver Anexo 1). Este análisis nos permitirá, seguidamente, profundizar en la forma en que las organizaciones político-militares salvadoreñas utilizaron los recursos que la prensa clandestina puso a su alcance, facilitándonos reconocer los diferentes modelos comunicativos impulsados por cada estructura y sus implicaciones en el desarrollo organizativo de ambos partidos.

Una primera lectura de este análisis de contenido permite identificar la práctica ausencia de información -entendida en un sentido estricto como información periodística-, categoría que queda limitada a notas breves de ámbito nacional e internacional y a algunos artículos de corta extensión relacionados a conflictos sociales. Este hueco informativo es cubierto, en las publicaciones clandestinas analizadas, 
por artículos y análisis coyunturales, no ausentes de información, pero en los que se hace evidente una vocación principalmente doctrinal. Esta priorización de los contenidos teóricos en las publicaciones de la izquierda revolucionaria ha sido explicada por algunos historiadores de la comunicación en un doble sentido. Por un lado, como un esfuerzo por abrirse espacios políticos ya ocupados, lo que obligaría a las organizaciones emergentes a "redoblar sus esfuerzos de convencimiento ideológico a través del bombardeo doctrinal"22. Por otro lado, señala Ibarra, las organizaciones de la izquierda radical otorgan mayor importancia a la formación de sus militantes que los partidos tradicionales. Esta motivación adquiere mayor peso si cabe en el caso de los grupos clandestinos y de las organizaciones político-militares, caso que nos ocupa, en los que la detención o la muerte de sus dirigentes es una posibilidad real y habitual, en cuyo caso las actividades que estos desarrollan deberían pasar a ser realizadas por otros militantes.

En contraposición a una escasa representación de contenidos informativos, encontramos, como indicamos, una presencia muy destacada de contenidos de naturaleza doctrinal, pero también identitarios, categoría esta última que ha sido agrupada bajo el enunciado "cultura partidaria" en los gráficos anteriores. Esta circunstancia, que no resultaría sorprendente en el caso de los órganos teóricos - Estrella Roja, para las FPL, y Prensa Comunista, para el ERP-, por su carácter esencialmente interno de los mismos, se encuentra también presente en los periódicos de distribución menos restringida. Este hecho nos permite advertir que si bien la prensa clandestina no rehuyó las tareas informativas propias de este tipo de comunicación -presente como hemos señalado en los análisis de coyuntura-, su utilización por las organizaciones revolucionarias se orientó fundamentalmente a la proyección de posiciones y objetivos políticos y a la consolidación de procesos de construcción identitaria. Procesos de radicalización y conversión ideológica, que se venían avanzando, al menos, desde finales de la década de 1960, en función de redes sociales previas al surgimiento de las organizaciones armadas, y que encontrarían en la prensa clandestina una herramienta de movilización adecuada — siempre en relación con otros factores (organización política, redes sociales, contexto represivo, etc.) - en el marco de un ciclo expansivo de la protesta y de creciente movilización social.

\section{Organizador colectivo}

Gabriel Santullano, en sus conclusiones generales sobre la funcionalidad de la prensa clandestina, apunta acertadamente que 
toda la producción de información, opinión, contenido doctrinario, educativo, los elementos de cohesión presentes en las publicaciones clandestinas, tenían un objetivo último: "conducían finalmente a la acción. El periódico se convertía en guía, en 'grito de combate' ${ }^{\prime \prime 23}$. La prensa clandestina asumía, en este sentido, un carácter agitativo y de orientador para la acción, pero fundamentalmente, adquiría la función de organizador colectivo.

Las publicaciones clandestinas fueron, en muchos casos, el primer contacto de los futuros militantes de la guerrilla con las organizaciones a las que se acabarían integrando. Fue el caso de José Álvarez, posteriormente responsable del Equipo de Propaganda de las FPL, quien antes de ser invitado a sumarse a esta organización había conocido y discutido los contenidos de EI Rebelde y participado en su distribución ${ }^{24}$. También futuros dirigentes de esta organización, como Salvador Sánchez Cerén "Leonel González", recogen en sus memorias la utilización de la prensa clandestina como herramienta para el reclutamiento:

"En ese tiempo (...) las FPL nos planteó al grupo que nos veníamos reuniendo en Quezaltepeque con Darío el ingreso en sus filas. Nos entregaron materiales que explicaban qué eran las FPL, cuáles eran sus objetivos, sus principios ideológicos, cuál era la visión de un país diferente, las operaciones que habían realizado; al comenzar a leer toda esa propaganda decidimos tener reuniones con la persona de contacto, esa fue mi entrada a la organización. Al mismo tiempo en ANDES se dio un reclutamiento importante y fue a través de Mélida Anaya Montes (...) Yo le dije que un grupo de maestros nos reuníamos con una persona de Colón y que a través de él habíamos entendido qué eran las FPL. Ella respondió: "Si usted quiere le voy a poner en contacto directo" y yo le contesté afirmativamente y me comenzó a pasar el periódico El Rebelde que era el órgano de las FPL"25.

La prensa clandestina no sólo fue una herramienta básica en la captación y reclutamiento de simpatizantes, cumpliendo una función proselitista, sino que en la mayoría de casos las primeras actividades de estos nuevos componentes estaban vinculadas precisamente con el reparto y distribución de propaganda.
El mismo Sánchez Cerén recuerda como una de sus primeras tareas como militante los operativos de reparto de El Rebelde en Quezaltepeque, cuando todavía no era miembro de célula y participaba en un grupo de apoyo a las $\mathrm{FPL}^{26}$. También en el ERP las actividades de propaganda serían utilizadas como una forma de 
foguear al combatiente. Juan Ramón Medrano 'Comandante Balta', relata en sus memorias su primera acción de propaganda armada en 1972, consistente en una pinta y distribución de volantes: "no habíamos tenido ningún tipo de entrenamiento militar previo, pues esa era una de las primeras actividades de prueba para nosotros, ya que recién nos habían reclutado para la guerrilla" 27 .

Pero la importancia de la prensa clandestina no sólo recayó en su ca- lidad de herramienta para el reclutamiento. Alrededor de su producción, distribución y lectura se aglutinaría y cohesionaría la militancia orgánica. La lectura de la prensa partidaria - después lo sería la escucha de radio en los frentes de guerra- era una tarea obligatoria en la mayoría de estructuras clandestinas y su elaboración y distribución implicaba a la organización en su conjunto. Un ejemplo de ello, lo aporta Eduardo Sancho en relación a la elaboración de Por la causa proletaria:

"Por la causa se comienza a editar en mimeógrafos manuales... picábamos en esténcil. Nosotros éramos quienes lo trabajábamos, lo producíamos y después se reproducía. El sistema organizativo se llamaba el 'tres-tres'. Suponete que éste traía su periódico y veía a tres abajo, que no se conocían entre sí. Cada uno de ellos volvía a preproducir Por la causa, y se iba multiplicando la red, este es el 'tres-tres'"'28.

Las publicaciones clandestinas cumplieron también un efecto moralizador: en zonas donde no existía una presencia continuada de las organizaciones clandestinas o su estructura era débil, la prensa mantenía viva la esperanza del militante, trasladando además las orientaciones y líneas de acción para la coyuntura. Si el periódico llegaba es que la organización existía y se mantenía activa. El mismo razonamiento, pero con intereses opuestos, seguían las fuerzas de seguridad, como comprobaban los presos políticos:

"Esta fue la primera vez, después de varios meses, que teníamos noticias de la propaganda y operatividad militar del Partido, pues de alguna forma siempre los cuerpos represivos tenían en sus manos tanto "Rebeldes" como algunas otras publicaciones. Pensaban en la Guardia que el hecho de que no cayera propaganda del Partido (PRS-ERP) era una muestra de lo acorralado que se encontraba" ${ }^{\prime 2}$.

Herramienta para el reclutamiento y elemento de cohesión del grupo, son algunas de las funciones que hacia lo interno cumplió la 
prensa clandestina. Sin embargo, las publicaciones clandestinas incidieron en forma destacada en el desarrollo y crecimiento orgánico de las organizaciones político-militares, en la apertura de trabajo político en sectores sociales no organizados, y consolidando los modelos organizativos con que los grupos insurgentes se dotaron para su movilización. Nos detendremos, finalmente, a analizar estos procesos, apuntando las diferencias que, en este sentido observamos entre un modelo de prensa centralizado como la de las FPL y un modelo caracterizado por una mayor autonomía en el caso del ERP.

El surgimiento de Por la Causa Proletaria, como señalamos con anterioridad, estuvo ligado a fuertes cuestionamientos internos en el seno del ERP, pero su objetivo final no fue otro que dar respuesta al gran desarrollo que venía experimentando el movimiento social en El Salvador. Este fenómeno no afectaría sólo a la prensa del ERP, sino que por el contrario estaría en el origen de la prensa sectorial que las FPL comenzarían a desarrollar desde 1972, para atender a sectores específicos, a través de cabeceras como El Campesino Rebelde y Juventud Rebelde. Si bien el crecimiento del movimiento social fue una de las razones del impulso de la prensa clandestina por parte de ambas organizaciones, la forma de dar respuesta a esta situación será bien diferente en cada caso, proyec- tando las estructuras organizativas predominantes en cada organización en los modelos comunicativos recién iniciados.

El ERP, en el marco de la línea política de Resistencia Nacional, comenzaría a editar, además de Por la Causa Proletaria, diferentes órganos de propaganda, entre ellos Despertar Campesino, Bandera Roja, El Artillero, Trinchera Juvenil y Pensamiento Proletario ${ }^{30}$. Lejos de mantener una unidad editorial, cada una de estas cabeceras adhería a los diversos grupos o federaciones que en ese entonces convivían en el seno del ERP y, en consecuencia, defendían los planteamientos mayoritarios en cada uno de los sectores. Su elaboración, impresión y distribución se realizaba atendiendo a estos criterios sectorizados y federativos, al punto que una vez fragmentada la organización, la RN haría responsable a esta multiplicidad de medios de fomentar la dispersión ideológica en el ERP, "confundiendo a la militancia y a las masas que tenían acceso a estas publicaciones $^{\prime \prime 31}$.

Marco Hernández, miembro de una de las estructuras originarias del ERP y responsable de la edición de El Combatiente, apunta que la existencia de órganos y publicaciones diferenciadas según el sector, puede rastrearse desde el mismo origen de la organización: "el primer periódico que surgió era El Combatiente, porque servía para dar los partes 
militares (...) Eso dependía del sector o de la federación que se había desprendido de la disidencia comunista. Los otros sectores tenían sus propios órganos de divulgación (...) Bandera Roja, El Artillero, Despertar Campesino, eso respondía a otras federaciones" ${ }^{\prime \prime 2}$.

En síntesis, este modelo comunicativo, caracterizado por la autonomía y la disparidad de planteamientos, reflejaba la propia estructura federativa con la que había surgido el ERP y con la que, todavía en ese momento, seguía funcionando esta organización. "Había autonomía porque — el del ERP — no era en ideas y debate un centralismo como en las FPL (...) Los leninistas veían que era dispersión. Nosotros, no. Nosotros creíamos que cada sector iba a interpretar su interés gremial, sus reivindicaciones" ${ }^{\prime 3}$, explica Eduardo Sancho, para quien esta autonomía facilitó, posterior- mente, el rápido crecimiento de la prensa clandestina vinculada al Frente de Acción Popular Unificada (FAPU).

Si la prensa clandestina vinculada al ERP puede definirse por ese carácter federativo $y$, en cierto modo, autónomo, el modelo comunicativo de las FPL es, por el contrario, centralizado y se encuentra profundamente vinculado a la organización y la estructura con la que este partido se fue dotando en los primeros años de la década de 1970. Salvador Cayetano Carpio 'Marcial', máximo dirigente de las FPL, explica en su "Cuaderno $N^{\circ} 3$ " el desarrollo organizativo experimentado en el periodo 1973-1974, a raíz de la creación de diferentes Comisiones Nacionales (Masas, Militar, Relaciones, Organización, Propaganda, Educación, Finanzas), que apoyaran el trabajo político del Comité Central:

"A partir de las subcomisiones, para la dirección orgánica se forman buena cantidad de Equipos Nacionales. Desde aquí, tenía que llevarse la línea, por sí misma y por sus propios hombres, organismos y redes hasta el último rincón del país: para el campesino, para el maestro, para los estudiantes. Un esquema gremialista de dirección del partido y organización interna para dirigir los movimientos de masas" ${ }^{\prime \prime 4}$.

Bajo este mismo esquema organizativo, las FPL edificarían un modelo comunicativo, con una publicación central, El Rebelde, que se apoyaría en la edición de numerosas cabeceras sectoriales, dirigidas a grupos sociales específicos, pero que, a diferencia de la prensa federativa del ERP, compartían una misma línea editorial. Así, junto a El Campesino Rebelde ${ }^{35}$ y Juventud Rebelde, este último dirigido a los estudiantes universitarios, las FPL comenzarían a editar durante esta 
década cabeceras como Prensa Obrera, para el movimiento obrero; El Guerrillero, para los estudiantes de secundaria; Magisterio Rebelde, en un esfuerzo por atraer al combativo gremio docente; Guerra Popular, para la organización en los tugurios; Soldado Rebelde, publicación dirigida al trabajo político en las Fuerzas Armadas; y, finalmente, la publicación dedicada a la mujer, Compañera.

Esta centralidad del modelo comunicativo tendría su reflejo no sólo en los contenidos de las publicaciones, sino en la propia redacción, edición y distribución de los mismos. José Álvarez, a cuyo cargo estaba el principal taller de propaganda de las FPL, asegura que la totalidad de las publicaciones - tanto El Rebelde, como las publicaciones sectoriales-, al menos hasta 1976, se compaginaban e imprimían en un mismo lugar, desde donde eran distribuidas al resto del país. Respecto a la redacción de estos materiales, aunque existía un equipo de prensa encargado de recopilar las noticias, esta correspondía a la Comisión Política y ninguna edición podía publicarse sin haber sido supervisado por esta. Al respecto, recuerda:

"En una ocasión, no llegaba material. Siempre venía la información de la Comisión Política, del Comité Central, y en esa ocasión, no. Bueno dije yo, no vamos a dejar de publicarlo, entonces me puse a escribir en base a toda la información que teníamos y ya terminado, editado todo El Rebelde, me dicen: no, vos no estás autorizado. Pero la verdad es que teníamos capacidad para hacerlo, no sólo técnica, sino política e ideológica, pero no te lo permitían (...) Quien teníamos más de la mano o casi siempre con nosotros era Salvador Cayetano. El siempre estaba allí. Prácticamente vivía en el local de nosotros, aunque tuviera otros tres o cuatro locales más, pero el siempre estaba pendiente, desde el punto o la coma, hasta el contenido"36.

\section{Ideología y nuevos marcos interpretativos}

Desde una perspectiva eminentemente funcional, podemos afirmar que la prensa clandestina permitió a las organizaciones insurgentes, especialmente en su etapa inicial, dotarse de una herramienta propagandística con la que visibilizar su propia existencia. En esta línea, las publicaciones funcionaron como un soporte publicitario para las acciones armadas realizadas por estos grupos. Pero fueron más allá, permitiendo enmarcar toda esta actividad militar, dotándola de un contenido 
político y explicitando sus motivaciones y objetivos no sólo entre sus propios militantes, sino hacia la sociedad salvadoreña en su conjunto.

La prensa clandestina asumía, de esta manera, una función doctrinaria en una doble dirección. En primer lugar, como soporte de nuevos marcos interpretativos, en el sentido que le otorgan Snow y Benford, es decir, como elaboración de un diagnóstico que incluye la identificación de un problema y la atribución de culpabilidad o causalidad $^{37}$. Y en segundo lugar, como una herramienta para hacer comprensibles y asumibles estos nuevos marcos tanto entre su militancia, como entre amplios sectores de la sociedad. O lo que es lo mismo, dotando a estos grupos con las creencias necesarias para el cuestionamiento de determinadas situaciones y para su movilización:

"El Rebelde tenía una proyección más popular, más pública. Pero también se trataban temas como la concepción, el porqué de la estrategia de guerra popular prolongada, en qué nos basábamos. Algunos artículos iban ahí. Lo único es que en un lenguaje popular, que permitiera que la gente lo entendiera fácilmente. Porque tú agarras un documento sobre marxismo... puta, tenés que pensarlo bien" ${ }^{\prime 38}$.

Como señala Benjamín Tejerina, los movimientos sociales representan "una alternativa a una forma determinada de definir e interpretar la realidad". Su sentido es precisamente el cuestionamiento de los discursos mantenidos desde el poder, siendo una de sus características la capacidad de generar significados y discursos alternativos. La creación de estos discursos por parte de los movimientos sociales se genera, fundamentalmente, a través de las redes sociales, donde los sujetos debaten, cambian impresiones, analizan la realidad, contrastan sus puntos de vista en el seno del grupo, configurando un discurso propio y compartido sobre la situación social en la que se desenvuelven, sus problemas, responsables y posibles soluciones ${ }^{39}$. Como bien ha demostrado Alberto Martín Álvarez para el caso salvadoreño, las redes sociales en las que se desenvolvían los primeros militantes de las organizaciones guerrilleras reforzaron un sistema de creencias adquirido en una socialización política temprana, donde los valores de justicia social y solidaridad ocupaban un lugar primordial. La pertenencia a estas redes permitió a estos grupos desarrollar sus opiniones políticas, al entrar en contacto con sistemas de creencias más estructurados como el marxismo, fomentando su participación en movimientos sociales de protesta e iniciando procesos de radicalización, fruto de los altos ni- 
veles de represión a los que fueron sometidos ${ }^{40}$.

Estas redes tuvieron su dimensión "orgánica" en la creación de círculos de estudio de marxismo, estructuras generadas a iniciativa del PCS en los años 60 y que posteriormente reprodujeron las organizaciones político-militares, entre finales de esta década e inicios de los años 70, en la Universidad de El Salvador (UES) y en la enseñanza secundaria. Si bien estos círculos permanecieron con mayor o menor actividad a lo largo de la década, actuando como herramientas de socialización política para los nuevos militantes de la guerrilla, diversos factores relativizan su incidencia desde 1972. Desde un ámbito externo a las organizaciones insurgentes, la UES sufrió la intervención militar de sus instalaciones el 19 de julio de 1972, situación que se prolongaría hasta finales de $1973^{41}$, dificultando la actividad de estos círculos de estudio e instalando altos niveles de represión sobre la población universitaria. En el ámbito interno, las organizaciones guerrilleras, si bien venían actuando ya en forma clandestina, experimentaron un proceso de compartimentación aún mayor, a raíz de sus primeras acciones públicas —el ERP en marzo de 1972 y las FPL en agosto de ese mismo año-. En este contexto de aumento de la represión y de progresiva clandestinización de las organizaciones insurgentes, la estrategia de reclutamiento y forma- ción de simpatizantes predominante hasta ese momento, en base a las redes personales y a los círculos de estudio, necesitó diversificarse.

Consideramos que en esta diversificación de las estrategias de reclutamiento y consolidación orgánica la prensa clandestina jugó un papel destacado. No debe pasarse por alto el hecho de que el grueso de la prensa clandestina aparezca en este periodo (1972-1973). Y es que en las nuevas condiciones en las que se desarrollaban las organizaciones insurgentes, la prensa clandestina se mostró, primero, como una herramienta adecuada para el debate teórico interno y para la discusión e intercambio con otras organizaciones. En segundo lugar, actuó como un vehículo de transmisión eficaz para la homogeneización y consolidación del discurso de estas organizaciones, en un contexto de mayor compartimentación. Finalmente, y consideramos que este su mayor aporte en el periodo, la prensa clandestina actuó como un instrumento central en la extensión de estos discursos más allá de las estructuras partidarias, de las relaciones personales y de los ámbitos sociales en los que se habían conformado estas organizaciones - fundamentalmente el movimiento estudiantil-, en un momento en que estos grupos buscaban crecer orgánicamente e incidir políticamente sobre el movimiento social en su conjunto $y$, en forma específica, en el movimiento obrero. 
Si centramos el análisis de contenido en la temática de carácter doctrinal de los periódicos clandestinos, observamos que este discurre sobre tres ejes fundamentales: el análisis de la sociedad salvadoreña, las desigualdades y opresión que definen la necesidad de un cambio, aspecto que fundamenta la actuación de las organizaciones guerrilleras; una caracterización del enemigo: contra quién se combate; y finalmente, una problematización sobre las formas de lucha, que discurre sobre la antítesis entre lucha electoral y lucha armada. Aunque está presente en el conjunto de la producción editorial, especialmente en el caso de las FPL, existe un cuarto eje que adquiere especial relevancia hacia el final de la década de 1970 y se refiere al carácter regional del conflicto: la centroamericanización de la guerra revolucionaria.
Es interesante señalar que los ejes centrales que abordan las publicaciones clandestinas coinciden plenamente con los tres aspectos en los que, según Gamson ${ }^{42}$, debe incidir el discurso de los movimientos sociales: injusticia, identidad y eficacia. El primero, como ya hemos señalado, fundamenta la propia existencia de las organizaciones de oposición. El segundo busca generar un sentido de pertenencia, un "nosotros" $y$, en consecuencia, un "ellos", el enemigo. El tercero persigue que los integrantes del movimiento asuman que sus acciones pueden ser eficaces para conseguir los objetivos propuestos. En el caso que nos ocupa, este último rasgo aparece tremendamente definido y parte de la evidencia, para las organizaciones insurgentes, de la ineficacia de la participación electoral y de la represión sobre el movimiento popular, para determinar la vía armada como única posible para el éxito revolucionario.

\section{Prensa clandestina e identidades colectivas}

Hemos explicado, siguiendo a Ibarra, cómo las organizaciones de la izquierda radical, en un esfuerzo por conquistar políticamente espacios ya ocupados, refuerzan la carga doctrinal en sus posiciones y propuestas de intervención. Pizzorno aborda este fenómeno enmarcándolo en un proceso de construcción identitaria. Para este autor, mientras los grupos antiguos encuentran representación para la defensa de sus intereses, los grupos emergentes pugnan por ser reconocidos como representantes de nuevos intereses, utilizando para ello un procedimiento que define como de "formación de identidades colectivas". En este proceso, señala Pizzorno, es frecuente que estos grupos polaricen sus posiciones, adopten opciones de coherencia ideológica y definan objetivos no realistas. Estas acciones, que no se explicarían desde la perspectiva de maximización de los beneficios 
personales, encuentran su lógica y adquieren significado desde el punto de vista de la consolidación de una identidad general ${ }^{43}$.

Siguiendo la propuesta de Melucci, entendemos que las identidades colectivas suponen la existencia de aspectos cognitivos en relación a una definición de los medios de acción, sus objetivos y el ámbito de la acción colectiva; implican la presencia de una red de relaciones en las que los militantes discuten, se influencian y toman decisiones; $y$, finalmente, precisan de un grado de implicación emocional, permitiendo la identificación de un "nosotros" 44 . Nos interesa entonces profundizar en qué forma la prensa clandestina incidió en la conformación de estas identidades colectivas si, como afirma Melucci, éstas responden a una construcción social por parte de individuos o grupos que forman parte de un movimiento social. Para ello, nos detendremos en los elementos, tanto ideológicos como de carácter simbólico, presentes en las publicaciones clandestinas y empleados en pos de la cohesión interna del grupo, de la homogeneización de su militancia y, en última instancia, buscando la consolidación de identidades colectivas.

Las publicaciones clandestinas van a configurar esta identidad sobre la base de tres ejes centrales: la lucha armada, la cultura partidaria y la figura del mártir. Cada uno de estos ejes reforzará un sentido final.
La lucha armada se estructurará como un elemento diferenciador respecto a otras corrientes de la izquierda salvadoreña, en especial el Partido Comunista. La construcción de una cultura partidaria no hará otra cosa sino reforzar los elementos con los que se identifican los propios integrantes de cada organización, buscando homogeneizar a su militancia. Por último, la figura del mártir permitirá asumir los esfuerzos y sacrificios ya realizados, proyectándolos hacia un futuro que se pretende mejor. Seguidamente, nos detendremos en cada uno de estos aspectos.

Como hemos señalado, un elemento fundamental en la construcción identitaria es el relativo a la lucha armada. Buena parte de los esfuerzos de las publicaciones clandestinas se centran precisamente en legitimar esta forma de acción política y a los actores que la impulsan. Este tipo de contenidos se enmarcan en una lógica de oposición en la que implícitamente se establece una relación entre militancia y acción armada. En este sentido, el militante revolucionario es representado principalmente mediante la figura del guerrillero, del activista clandestino, y las acciones armadas son presentadas como la forma más elevada de lucha en esta estrategia de oposición. La lucha armada no sólo es legitimada, sino que se busca mostrar su eficacia, mediante la inclusión de partes de guerra y artículos sobre operativos militares. Es- 
tos contenidos tienen, como afirma Pérez Silva ${ }^{45}$, una doble intencionalidad. Para los ya convencidos, elevar la moral y reforzar la confianza en el camino emprendido. Y para los todavía indecisos, mostrar a un enemigo vulnerable, constantemente golpeado por las organizaciones revolucionarias.

La representación del revolucionario como "militante armado", de la que hablábamos anteriormente, tiene su reflejo gráfico en las cabeceras de prensa. Si nos centramos en la prensa sectorial de las FPL, observaremos al campesino trabajando el campo y alzando un fusil ${ }^{46}$, la mujer dándole el pecho a su hijo mientras carga un arma al hombro ${ }^{47}$, el estudiante secundario, sosteniendo un fusil y leyendo un libro $^{48}$, al igual que los universitarios $^{49}$. La misma caracterización se repite con el maestro, que armado guía a una fila de alumnos ${ }^{50}$ y les muestra el futuro socialista ${ }^{51} y$, por supuesto, el obrero, que avanza sobre la represión, recogiendo las armas de los caídos en la lucha ${ }^{52}$.

Esta forma de representación persigue mostrar al combatiente como la forma más elevada de militancia, estableciendo con ello una diferenciación fundamental con aquellas organizaciones que no asumen la lucha armada, y generando además una mística respecto al activista clandestino y a la misma clandestinidad. Mística que sobrepasa el terreno estricto de la mili- tancia para adentrarse en normas de comportamiento ético y moral, en la forma de relacionarse con el resto de la sociedad y en los modos de expresión cultural y artística. En el fondo, como apunta Della Porta, esta construcción de una identidad militante, junto a la socialización ideológica y la interacción en las redes del movimiento, permiten sostener el compromiso del activista ${ }^{53}$, en una situación en la que el militante clandestino rompe los lazos con aquellos que antes formaban parte de su mundo.

El segundo elemento que distinguimos en la construcción identitaria es aquel que remite a la homogeneización del militante. Hemos señalado con anterioridad como uno de los rasgos principales de la prensa clandestina es la gran presencia de contenidos doctrinales. Sin duda, como apunta Santullano, las publicaciones clandestinas sirvieron para transmitir un "criterio de cohesión doctrinal para los militantes del grupo ${ }^{\prime 54}$. Consideramos, sin embargo, que otros aspectos con mayor carga identitaria que doctrinaria incidieron igualmente en esta homogeneización de los militantes de las organizaciones guerrilleras. Nos detendremos específicamente en la conformación de una "cultura partidaria".

Esta cultura tendrá su representación en las publicaciones clandestinas a través de contenidos que remiten a la vida interna de 
las organizaciones, como la celebración de congresos ${ }^{55}$ y reuniones partidarias ${ }^{56}$, la publicación de los documentos y resoluciones acordadas en estos ${ }^{57}$, la creación de organismos $^{58}$ y nuevas estructuras partidarias ${ }^{59}$, los acuerdos alcanzados con otros grupos ${ }^{60}$ e informes sobre las actividades realizadas por la organización ${ }^{61}$. Otro segmento de contenidos, en este plano interno, se orientará a la publicación de sanciones disciplinarias, expulsiones o, por el contrario, informarán sobre la incorporación de nuevos militantes $^{62}$. Por otro lado, al comienzo de la década de 1980, las publicaciones comenzarán a abordar la vida de los militantes en los frentes de guerra, con un soporte fundamentalmente fotográfico ${ }^{63}$.

Un segundo grupo de contenidos remite a las influencias ideológicas de las organizaciones. En primer lugar, mediante la exaltación -gráfica y textual- de figuras del movimiento revolucionario internacional, desde los clásicos del marxismo-leninismo (Marx, Engels, Lenin, $\mathrm{Mao}^{64}$ ), iconos de la izquierda revolucionaria latinoamericana del periodo, como Ernesto Guevara $^{65}$, y personajes con fuerte carga emotiva para la izquierda salvadoreña, caso de Farabundo Martí66. En segundo lugar, a través de la conmemoración de hechos históricos de larga tradición en la izquierda — celebración del Primero de Mayo, triunfo de la revolución rusa-, y especialmente de hitos históricos en los que enmarca su desarrollo la izquierda revolucionaria salvadoreña: la insurrección de 1932, el asalto al Moncada, el triunfo de la revolución cubana, la masacre de estudiantes el 30 de julio de 1975. Debemos precisar que si bien el grueso de las publicaciones comparte este tipo de contenido, mientras su aparición es una constante en el caso de El Rebelde, su inclusión es, por el contrario, residual en El Combatiente.

En relación con lo anterior, cabe destacar la presencia de contenidos que conmemoran fechas clave en el desarrollo de las organizaciones revolucionarias: surgimiento, acciones fundacionales, primeros militantes caídos. Informaciones que se vinculan a una reelaboración constante de la historia de las organizaciones $^{67}$. Historia que es reescrita atendiendo a las diferentes coyunturas, que hace balance desde un plano generalmente autojustificativo, y que trata de superar crisis internas que pudieran poner en entredicho la continuidad organizativa. Esta reelaboración histórica debe entenderse como una proyección de futuro, que busca socializar los aciertos y errores cometidos por las organizaciones, haciendo partícipes incluso a aquellos que no tuvieron relación con los hechos narrados. En síntesis, se busca generar un sentido de pertenencia y que el militante asuma que si bien en el pasado se produjeron errores, estos fueron producto de los que 
ya no están o, simplemente, fueron superados. $Y$, en definitiva, que superados estos baches, se sigue en el camino correcto.

Un último elemento central en esta construcción identitaria, e íntimamente ligado al punto anterior, es la utilización de la figura del mártir. La representación de los caídos remite a un pasado de sacrificio, vinculando esos esfuerzos pasados, esa sangre derramada, con un futuro mejor por el que se sigue combatiendo. El mártir encarna, en esencia, la pureza, el ejemplo a seguir y ese es el tratamiento que le dan las publicaciones clandestinas, un tratamiento cuasi hagiográfico. Al mártir se le dedican poemas y canciones $^{68}$, se recuerda su vida ${ }^{69}$, su pensamiento ${ }^{70}$, pero fundamentalmente se le proyecta hacia la actualidad, haciéndolo partícipe del propio desarrollo y accionar de la organización, por ejemplo, bautizando con sus nombres operativos y campañas militares ${ }^{71}$.

Si bien ambas organizaciones - también lo haría la RN, al desprenderse del ERP - utilizarían en sus publicaciones estos recursos a la hora de proyectar y consolidar identidades colectivas entre sus militantes y simpatizantes, encontramos una notable diferencia en el peso que los contenidos de carácter identitario tienen en las publicaciones del ERP y de las FPL. Si esta disparidad ya es notable en el caso de las revistas teóricas - casi un 32\% de los contenidos de Estrella Roja tienen un perfil identitario, frente al $25,5 \%$ de Prensa Comunista-, la diferencia es mucho más pronunciada en el caso de las publicaciones de mayor difusión. Así, mientras El Rebelde dedica el $19,4 \%$ de sus contenidos en generar y consolidar una identidad como grupo, el espacio otorgado en El Combatiente a los aspectos identitarios apenas alcanzará un $6,6 \%$.

Esta presencia tan dispar de los contenidos identitarios no puede desligarse de otros factores claves en la propia dinámica de las organizaciones. Las diversas culturas políticas en las que se socializaron los primeros militantes de la guerrilla, la estructura con la que se dotaron las organizaciones, o la diferente forma de manejar la siempre tensa relación entre teoría y acción, incidió en la forma de verse a sí mismos y de proyectarse hacia la sociedad:

"La guerrilla tiene dos troncos. Lo que va a ser FPL y lo que va a ser ERP. Este -las FPL- más lineal, más homogéneo (...) es la pureza ideológica. Este - el ERP - lleva la vida intelectual clásica de América Latina, muchas ideas, mucha imaginación, mucha creatividad. Aquí vas a ver poetas, escritores, intelectuales, estudiosos (...) Ellos, por definición, son los representantes de la clase obrera y estos -ERP- 
son los representantes de las capas medias, que se vuelcan a articularse a dos clases: a obreros y campesinos"72.

Aunque no es el objetivo de este trabajo, consideramos oportuno cuestionarnos, al menos, en qué forma incidieron estos procesos identitarios que tuvieron lugar durante la década de 1970 en la evolución de ambas organizaciones, y en qué medida este fenómeno guarda relación con la dispersión experimentada por el ERP tras los acuerdos de paz y, por el contrario, en el mantenimiento de una "identidad FPL" en el seno del actual partido FMLN.

\section{Algunas conclusiones}

Del análisis realizado sobre los principales órganos periodísticos de las FPL y el ERP, podemos concluir que, si bien la prensa clandestina cumplió funciones tales como la información, la denuncia y tareas de corte propagandístico, su principal aporte para las organizaciones político-militares salvadoreñas durante la década de 1970 se orientó hacia un plano interno.

Como soporte para la discusión en el seno del grupo, el debate con otras organizaciones $y$, específicamente, en la proyección de sus posiciones y objetivos políticos hacia la sociedad salvadoreña en su conjunto. La prensa clandestina cumplió, en ese sentido, una función doctrinaria como soporte de nuevos marcos interpretativos, dotando a su militancia y grupos afines con las creencias necesarias para el cuestionamiento de determinadas situaciones y para su movilización.

Tras una primera etapa en que la base del crecimiento y el desarrollo organizativo de estos grupos se había cimentado sobre la existencia de redes sociales, conformadas con anterioridad al surgimiento de la guerrilla, y su actividad en la universidad, las organizaciones debieron afrontar una diversificación de sus estrategias de reclutamiento y consolidación orgánica. En un contexto de mayor compartimentación, con la universidad intervenida, y elevados niveles represivos, la prensa se consolidó como una herramienta adecuada para la homogeneización interna y para la apertura de trabajo político en nuevos sectores sociales.

La prensa clandestina no fue sólo soporte de nuevos marcos interpretativos sino que incidió en la conformación y consolidación de identidades colectivas sobre la base de tres ejes centrales: la defensa de la lucha armada, la creación de una cultura partidaria y la utilización de elementos de carácter simbólico, como la figura del mártir. 
Las publicaciones clandestinas asumirían una función de organizador colectivo. Cumplieron una función proselitista, sirviendo como herramienta para el reclutamiento y para foguear a los futuros combatientes, cuyas primeras actividades estaban vinculadas precisamente al ámbito de la propaganda. Alrededor de su producción, distribución y lectura se aglutinaba y cohesionaba la militancia $y$, en muchos casos, implicaba un componente moralizador, allí donde la organización tenía una presencia débil o el militante se encontraba aislado.

Por último, hemos apreciado cómo los modelos comunicativos impulsados por las FPL y el ERP están íntimamente ligados a las estructuras organizativas con que estos grupos se dotaron para la movilización, consolidando dos modelos diferenciados: un modelo federativo, caracterizado por cierta autonomía, en el caso del ERP, y un modelo centralizado, en su redacción, producción y distribución, para el caso de las FPL.

\section{ANEXO I.}

Para la elaboración de este trabajo se han analizado un total de 72 publicaciones centrales de las organizaciones objeto de estudio - ERP y FPL-, quedando al margen de esta cifra las publicaciones sectoriales a las que se hace mención en el artículo. Ciertamente, encontramos una limitación importante a la hora de contar con series completas, al tratarse de publicaciones clandestinas que se encuentran, en general, dispersas en diferentes centros documentales y archivos. Tan sólo en el caso de Estrella Roja se ha podido contar con una serie absoluta para el periodo analizado (1971-1980), siendo el más endeble el análisis de Por la Causa Proletaria, del que sólo se han podido analizar tres ejemplares, entre 1973 y 1974 —obviamos del análisis el estudio de ejemplares de PLCP publicados con posterioridad a diciembre de 1974, al pasar esta cabecera a convertirse en órgano de la Resistencia Nacional, tras la ruptura con el ERP. Para el resto de publicaciones, sin tratarse de series completas, estimamos que el análisis es suficientemente sólido, especialmente en el caso de los órganos de las FPL, por cuanto su aparición fue mucho más regular y sistemática que en el caso del ERP $y$, en consecuencia, también son más los ejemplares que pudieron conservarse $y$, en nuestro caso, ser analizados. Un hecho que no hace más que reflejar la diferente relevancia que cada organización otorgó a la prensa clandestina en su estrategia política.

El objetivo del análisis no es otro que sistematizar los contenidos de las publicaciones, buscando señalar la jerarquía que cada 
publicación otorgó a cada una de las categorías propuestas por Pedro Ibarra en su estudio sobre la prensa clandestina. Para ello, hemos optado por utilizar como unidad de análisis no artículos o segmentos de artículos, sino el número de páginas - espacio en relación a un artículo- en el que cada categoría se muestra. Entendemos que si bien esta elección no deja de plantear ciertos problemas metodológicos el resultado será más fiable que si usáramos como unidad de análisis el artículo, por cuanto un artículo puede ocupar desde un cuarto de página $-\mathrm{O}$ incluso menos - hasta decenas de páginas, especialmente cuando estamos abordando prensa política. Por otro lado, esta elección nos permite incluir contenidos gráficos - fotografías, dibujos, etc.-, que irán ganando presencia a lo largo de la década de 1970 en estas publicaciones, y que quedarían ausentes si optáramos por el artículo como unidad de análisis.

Por último, aunque nos parece evidente que diferentes categorías pueden estar presentes $-\mathrm{y}$ generalmente hemos podidos constatar que así ocurre - en una misma unidad de análisis, hemos optado por priorizar aquellas categorías que presentan mayor jerarquía en cada unidad analizada.

\section{PUBLICACIONES CLANDESTINAS DEL ERP}

Gráfico 1. Elaboración propia a partir de una serie incompleta entre abril de 1974 y noviembre de 1980

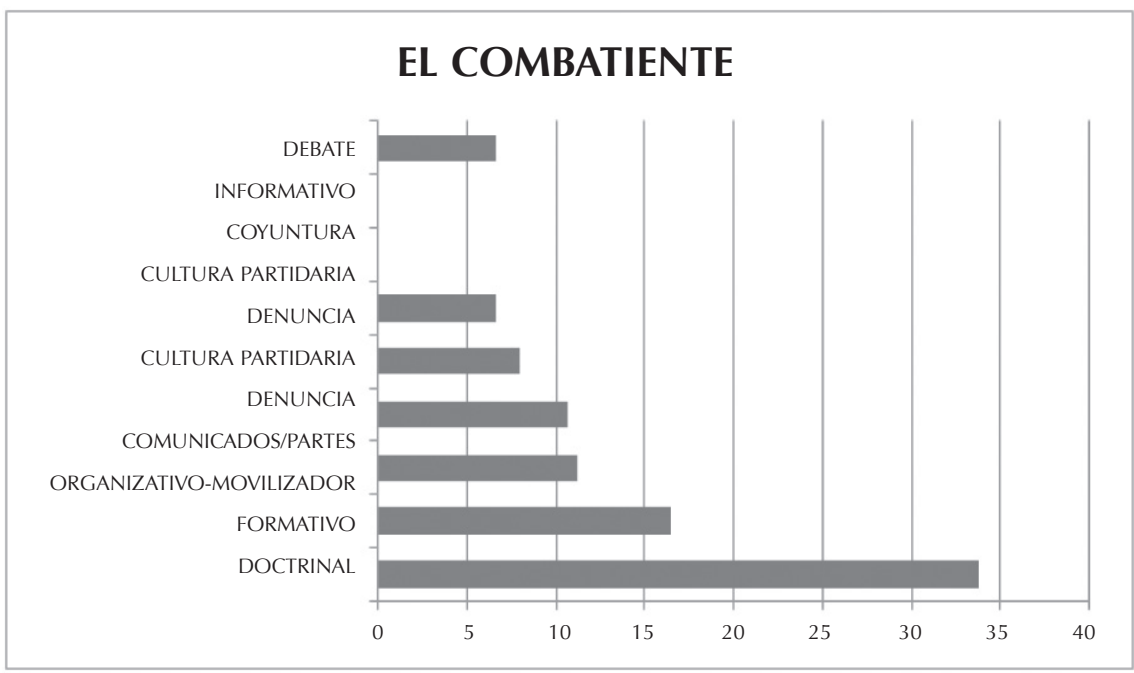


Gráfico 2. Elaboración propia a partir de una serie incompleta entre octubre de 1973 y diciembre de 1974

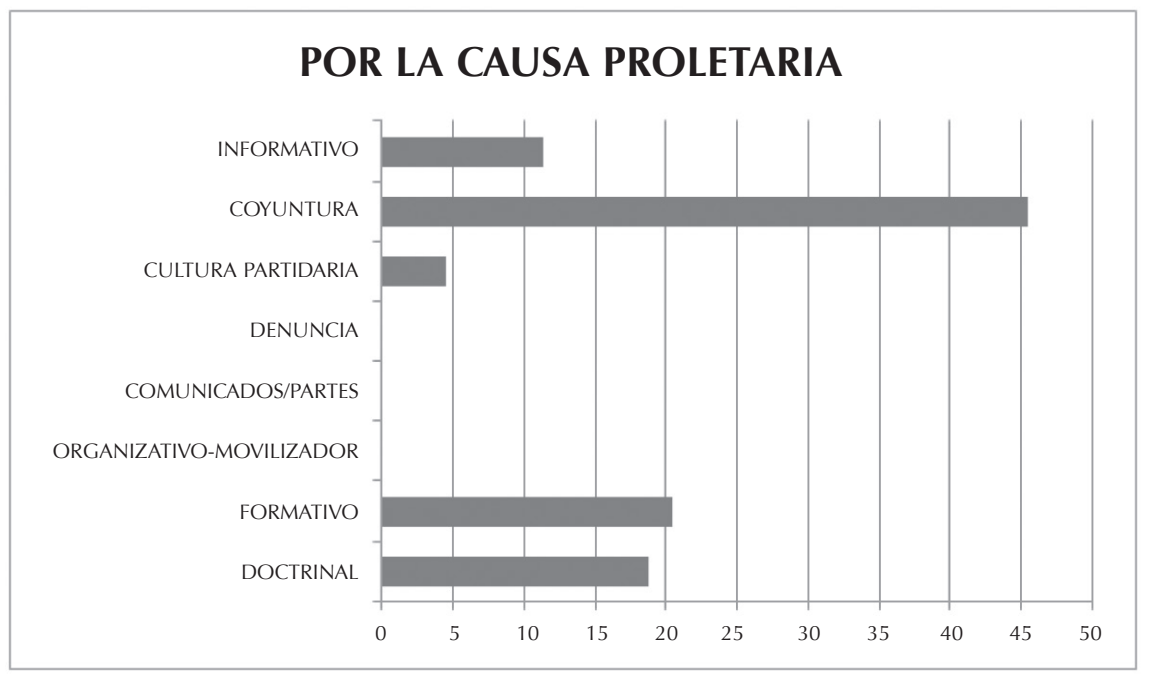

Gráfico 3. Elaboración propia a partir de una serie incompleta entre mayo de 1975 y septiembre de 1978

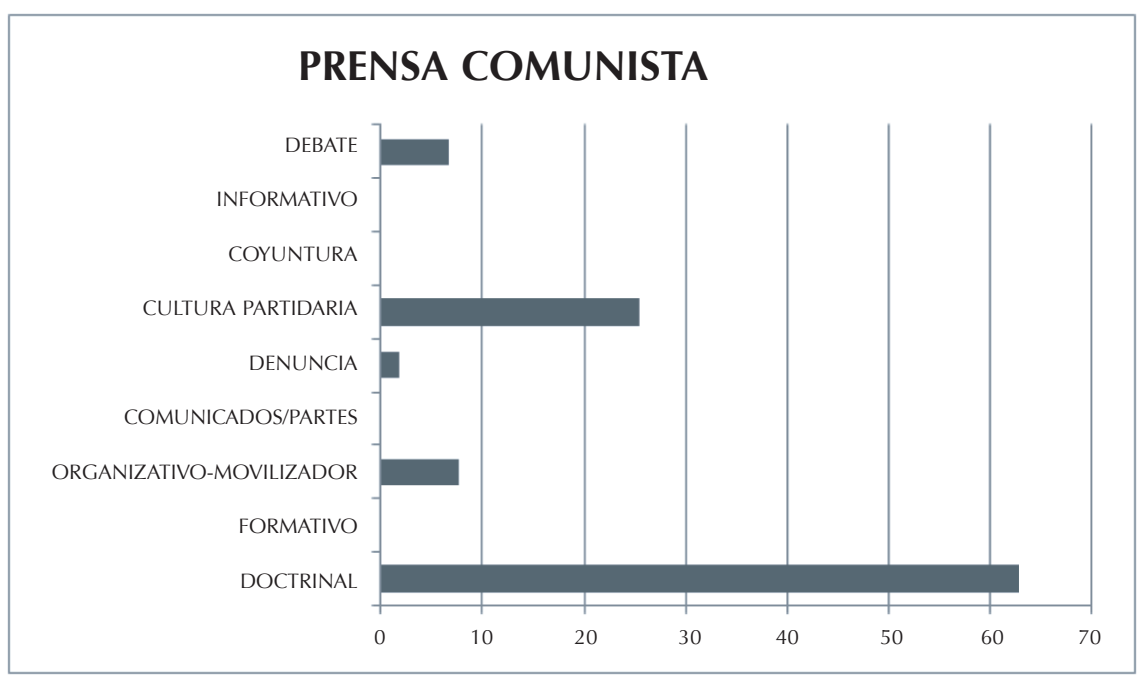




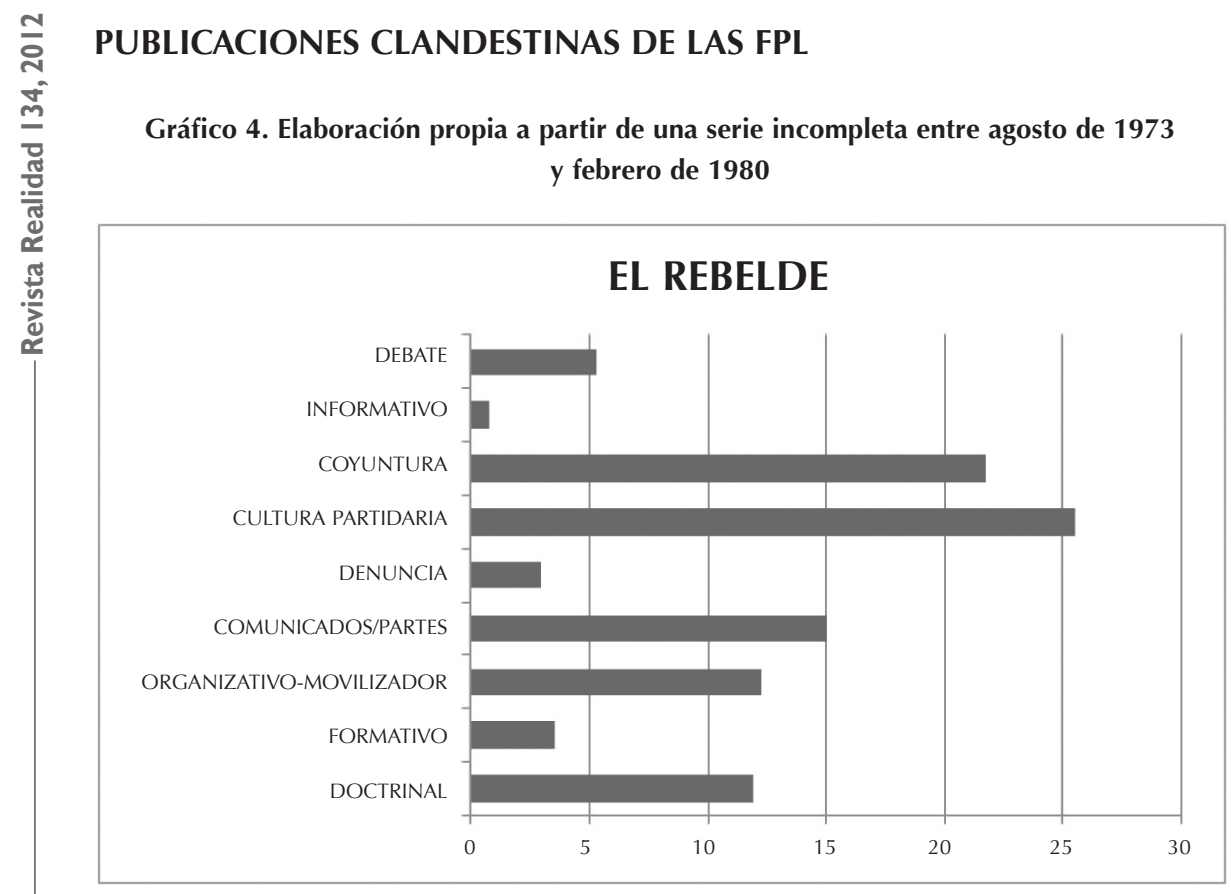

Gráfico 5. Elaboración propia a partir de una serie completa entre diciembre de 1973 y febrero de 1979

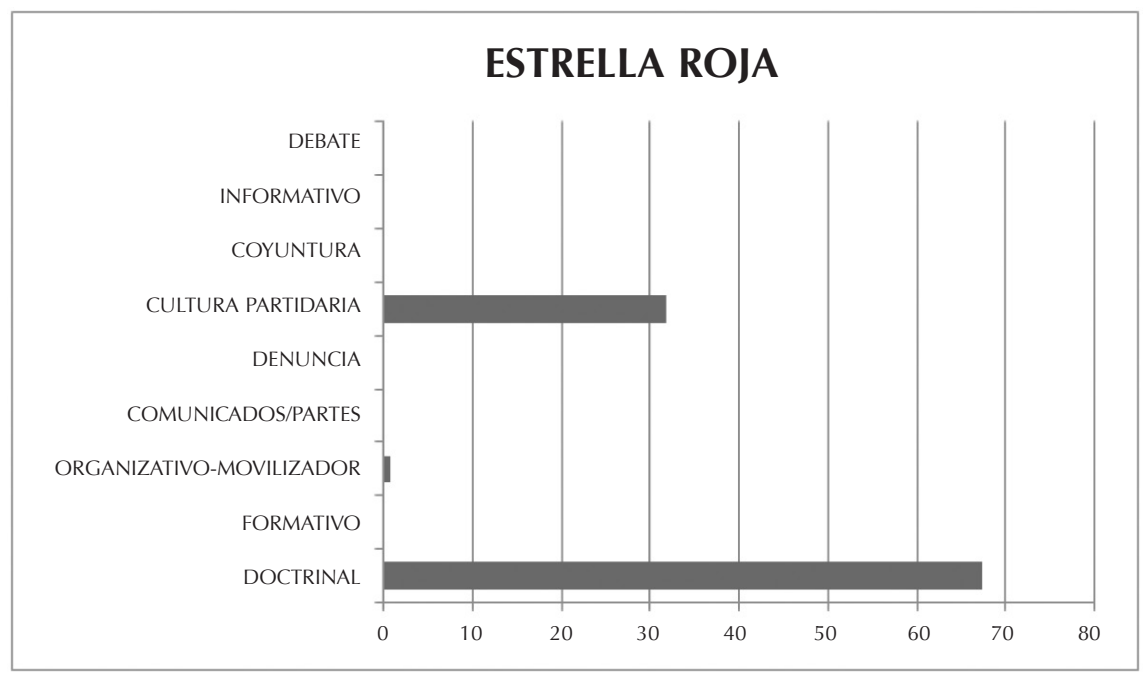




\section{Bibliografía}

- ALMEIDA, Paul. Olas de movilización popular: movimientos sociales en El Salvador, 1925-2010. San Salvador: UCA Editores, 2011.

- BASSETS, Lluís y BASTARDES, Enric. "La prensa clandestina en Catalunya: una reflexión metodológica". En VIDAL BENEYTO, J. Alternativas populares a las comunicaciones de masa. Madrid: CIS, 1979, pp. 155-175.

- CAYETANO CARPIO, Salvador. Nuestras montañas son las masas. Viena, Edition "Der Keil", 1999.

- DOMENACH, Jean-Marie. "La propaganda de tipo leninista". En DOMENACH, J. M. La propaganda política. Buenos Aires, Editorial Universitaria de Buenos Aires, 1963, pp. 23-34.

- ESCALONA, Teresa. "La radio como instrumento de lucha política: experiencia de Radio Farabundo Martí, 1982-1992". Ponencia en el Primer Encuentro de Historia de El Salvador, del 22 al 25 de julio de 2003.

- FLORES MACAL, Mario. "Historia de la Universidad de El Salvador". En Anuario de Estudios Centroamericanos de la Universidad de Costa Rica, Vol. 2 (1976), pp. 107-140.

- GAMSON, W. "The Social Psychology of Collective Action". En MORRIS, A.; McCLURG MUELLER, C. Frontiers in Social Movements Theory. New Haven: Yale University Press, 1992.

- HARNeCKer, Marta. Con la mirada en alto. Historia de las Fuerzas Populares de Liberación "Farabundo Martí" a través de entrevistas con sus dirigentes. Donostia: Gakoa, 1991.

- IBARRA, Pedro. "La prensa clandestina en Euskadi bajo el franquismo". En GARITAONANDIA, Carmelo (ed.). La prensa de los siglos XIX y XX. Metodología, ideología e información. Aspectos económicos y tecnológicos. Bilbao: Servicio Editorial Universidad del País Vasco, 1986, pp. 687-697.

- MARTíN ÁlVAREZ, Alberto. "Ideología y redes sociales en el surgimiento de violencia política: el Frente Farabundo Martí para la Liberación Nacional". En Actas del XIV Encuentro de Latinoamericanistas Españoles. Congreso Internacional "1810-2010: 200 años de Iberoamérica. Santiago de Compostela, Universidad de Santiago de Compostela, 2010), pp. 1620-1640.

Revolucionario del Pueblo (ERP) en El Salvador". Inédito. 
- MARTíneZ, Ana Guadalupe. Las cárceles clandestinas de El Salvador. Libertad por el secuestro de un oligarca. Sin pie de imprenta, 1978.

- MEDRANO GUZMÁN, Juan Ramón. Memorias de un guerrillero. Comandante Balta. El Salvador: New Graphics, 2008.

- MELUCCl, Alberto. Nomads of the Present: Social Movements and Individual Needs in Contemporary Society. Philadelphia: Temple University Press, 1989. "The Process of Collective Identity.". En JOHNSTON, Hank; KLANDERMANS, Bert. Social Movements, Protest, and Contention. Vol. 4. Social Movements and Culture. Minneapolis: University of Minnesota Press, 1995, pp. 41-63.

- MENÉNDEZ, Mario. El Salvador. Guerra civil y revolución. Proceso y protagonistas (El porqué de esta guerra). Bogotá: Editorial La Oveja Negra, 1980.

- PÉREZ SILVA, Claudio. "Violencia y política en las publicaciones clandestinas bajo Pinochet. La palabra armada en el Frente Patriótico Manuel Rodríguez. Chile, 1983-1987". En Revista de Historia Social y de las Mentalidades, No XII, Vol. 2, (Chile, 2008), pp. 71-90.

- PIZZORNO, Alessandro. "Identidad e interés". En Zona Abierta, № 69 (1994), pp. 135-152.

- PORTA, Donatella della. "Las motivaciones individuales en las organizaciones políticas clandestinas". En IBARRA, Pedro y Benjamín Tejerina. Los movimientos sociales. Madrid: Trotta, 1998, pp. 219-242.

- SABUCEDO, José Manuel; GROSSI, Javier; FERNÁNDEZ, Concepción. "Los movimientos sociales y la creación de un sentido común alternativo". En IBARRA, Pedro y Benjamín Tejerina. Los movimientos sociales. Madrid: Trotta, 1998, pp. 165-180.

- SÁNCHEZ CERÉN, Salvador. Con sueños se escribe la vida. Autobiografía de un revolucionario salvadoreño. México: Ocean Sur, 2008.

- SANTUlLANO, Gabriel. La prensa clandestina en Asturias. Oviedo: Fundación Juan Muñiz Zapico - KRK Ediciones, 2005.

- SNOW, D. A. y R. D. Benford. "Master frames and cycles of protest". En MORRIS, A.; McCLURG MUELLER, C. Frontiers in Social Movements Theory. New Haven: Yale University Press, 1992.

- TARROW, Sidney. El poder en movimiento. Los movimientos sociales, la acción colectiva y la política. Madrid: Alianza Editorial, 1994. 
- TEjeRINA, Benjamín. "Los movimientos sociales y la acción colectiva. De la producción simbólica al cambio de valores". En IBARRA, Pedro y Benjamín Tejerina. Los movimientos sociales. Madrid: Trotta, 1998, pp. 111-138.

- TILLY, Charles. "Conflicto político y cambio social". En IBARRA, Pedro y Benjamín Tejerina. Los movimientos sociales. Madrid: Trotta, 1998, pp. 25-41.

\section{Notas}

1 El presente artículo se inserta en el desarrollo la tesis doctoral sobre "Prensa clandestina y movimiento guerrillero en América Latina", que el autor avanza en el marco del proyecto de investigación INCITE09-210-098PR, financiada por la Dirección Xeral de Investigación e Innovación de la Xunta de Galicia.

2 Cada una de las organizaciones integradas en el FMLN intentaron poner en funcionamiento emisoras clandestinas. Algunas tuvieron muy corta vida, como Radio Unidad, del Partido Revolucionario de los Trabajadores Centroamericanos (PRTC), y Radio Guazapa, de la Resistencia Nacional. Otras lograrían emitir hasta el final del conflicto, caso de Radio Farabundo Martí, de las FPL, y de Radio Venceremos, impulsada por el ERP y a la postre emisora oficial del FMLN.

3 Salpress, controlada por las FPL, fue la agencia que alcanzó un mayor desarrollo. La RN impulsaría otra agencia informativa, curiosamente con el mismo nombre, posteriormente rebautizada con las siglas API. El Partido Comunista de El Salvador (PCS) haría lo propio fundando Notisal.

4 La primera experiencia de radio clandestina vinculada a las organizaciones revolucionarias salvadoreñas es Radio Revolucionaria del Pueblo, del ERP, que emitió en 1980 en San Salvador.

En ese mismo periodo una estructura de las FPL intentaría poner en marcha en Costa Rica una emisora, como lo había hecho Radio Sandino durante la insurrección sandinista. Con esta experiencia y parte de la infraestructura de este proyecto inconcluso, el FMLN pondría en funcionamiento en Nicaragua Radio Liberación, cuya finalidad era acompañar informativamente la ofensiva de enero de 1981.

5 MARTÍN ÁLVAREZ, Alberto. "Procesos de radicalización: el caso del Ejército Revolucionario del Pueblo (ERP) en El Salvador". Inédito.

6 "Comunicado $\mathrm{N}^{\circ} 1$ del Ejército Revolucionario del Pueblo". En Prensa Comunista Publicaciones Especiales (Octubre de 1977), p. 1.

7 Entrevista a Eduardo Sancho 'Fermán Cienfuegos', dirigente del ERP y de la RN. San Salvador, 31 de octubre de 2011.

8 Por la causa proletaria, No 25 (Marzoabril de 1976), p. 7.

9 Partido de la Revolución Salvadoreña (PRS) será la denominación con la que el ERP dotará a su estructura política tras la separación de la Resistencia $\mathrm{Na}$ cional.

10 "Nota de la redacción". En Por la causa proletaria, $\mathrm{N}^{\circ} 14$ (Diciembre de 1974), pp. 1-2. 
11 Entrevista a Eduardo Sancho. San Salvador, 31 de octubre de 2011.

12 "El Rebelde cumple su primer año". En El Rebelde, № 11 (Octubre de 1973), pp. 1-2.

13 HARNECKER, Marta. Con la mirada en alto. Historia de las Fuerzas Populares de Liberación "Farabundo Marti" a través de entrevistas con sus dirigentes. Donostia: Gakoa, 1991, p. 56.

14 "El Rebelde en las batallas decisivas". En El Rebelde (2 etapa), No 1 (Octubre de 1983), pp. 1-2.

15 "El Rebelde cumple su primer año". Op. cit.

16 "El Rebelde inicia el quinto año de su trabajo revolucionario". En El Rebelde, $\mathrm{N}^{\circ} 49$ (Noviembre de 1976), p. 12.

17 Bajo esta misma denominación, editaban un boletín la Juventud Comunista de El Salvador (JCS) y el Frente Unitario de Acción Revolucionaria Docente (FUARD), organización integrada en la Unión Democrática Nacionalista (UDN), estructura electoral del PCS.

18 "Presentación”. En Estrella Roja, N ${ }^{\circ}$ 1 (Diciembre de 1973), pp. 2-3

19 Entrevista a José Álvarez, responsable del Equipo Nacional de Propaganda de las FPL. San Salvador, 8 de noviembre de 2011 .

20 IBARRA, Pedro. "La prensa clandestina en Euskadi bajo el franquismo". En GARITAONANDIA, Carmelo (ed.), La prensa de los siglos XIX y XX. Metodología, ideología e información. Aspectos económicos y tecnológicos. Bilbao: Servicio Editorial Universidad del País Vasco, 1986, pp. 689-692.

21 BASSETS, Lluís; BASTARDES, Enric. "La prensa clandestina en Cataluña: una reflexión metodológica". En BENEYTO, J. V.(recopilador). Alternativas populares a las comunicaciones de masas Madrid: CIS, 1979, pp. 155-175.

22 IBARRA, Pedro. "La prensa clandestina en Euskadi bajo el franquismo". En GARITAONANDIA, Carmelo (ed.). La prensa de los siglos XIX y XX. Metodología, ideología e información. Aspectos económicos y tecnológicos. Bilbao: Servicio Editorial Universidad del País Vasco, 1986, p. 694.

23 SANTULLANO, Gabriel. La prensa clandestina en Asturias. Oviedo: Fundación Juan Muñiz Zapico - KRK Ediciones, 2005, p. 109.

24 Entrevista a José Álvarez. San Salvador, 8 de noviembre de 2011.

25 SÁNCHEZ CERÉN, Salvador. Con sueños se escribe la vida. Autobiografía de un revolucionario salvadoreño. México: Ocean Sur, 2008, p. 109.

26 Ibíd., p. 110.

27 MEDRANO GUZMÁN, Juan Ramón. Memorias de un guerrillero. Comandante Balta. El Salvador: New Graphics, 2008, pp. 51, 101-102.

28 Entrevista a Eduardo Sancho. San Salvador, 31 de octubre de 2011.

29 MARTÍNEZ, Ana Guadalupe. Las cárceles clandestinas de El Salvador. Libertad por el secuestro de un oligarca. Sin datos de edición, 1978, p. 295.

30 "Nota de la redacción". En Por la causa proletaria, $\mathrm{N}^{\circ} 14$ (Diciembre de 1974), pp. 1-2.

31 Por la causa proletaria, $\mathrm{N}^{\circ} 25$, p. 13.

32 Entrevista a Marco Hernández, militante del ERP y responsable de la edición de El Combatiente. El Salvador, 26 de octubre de 2011. 
33 Entrevista a Eduardo Sancho. San Salvador, 31 de octubre de 2011.

34 CAYETANO CARPIO, Salvador. Nuestras montañas son las masas. Viena: Edition "Der Keil", 1999, pp. 101-103.

35 El periódico dirigido al sector campesino se publicaría, posteriormente, con el nombre de Campo Rebelde.

36 Entrevista a José Álvarez. San Salvador, 8 de noviembre de 2011.

37 SNOW, D. A.; BENFORD, R. D. "Master frames and cycles of protest". En MORRIS, A.; McCLURG MUELLER, C. Frontiers in Social Movements Theory. New Haven: Yale University Press, 1992, pp. 138-141.

38 Entrevista a José Álvarez. San Salvador, 8 de noviembre de 2011.

39 SABUCEDO, José Manuel [et al]. "Los movimientos sociales y la creación de un sentido común alternativo". En IBARRA, Pedro y Benjamín Tejerina. Los movimientos sociales. Madrid: Trotta, 1998, pp. 170-173.

40 MARTÍN ÁLVAREZ, Alberto. "Ideología y redes sociales en el surgimiento de violencia política: el Frente Farabundo Martí para la Liberación Nacional". En Actas del XIV Encuentro de Latinoamericanistas Españoles. Congreso Internacional "1810-2010: 200 años de Iberoamérica. Santiago de Compostela: USC, 2010, p. 1635.

41 FLORES MACAL, Mario. "Historia de la Universidad de El Salvador". En Anuario de Estudios Centroamericanos de la Universidad de Costa Rica. 1976, Vol. 2, pp.134-135.

42 GAMSON, W. "The Social Psychology of Collective Action". En MORRIS, A.; McCLURG MUELLER, C. Frontiers in Social Movements Theory. New Haven: Yale University Press, 1992. Citado en SABUCEDO, José
Manuel [et al]. "Los movimientos sociales y la creación de un sentido común alternativo". En IBARRA, Pedro y Benjamín Tejerina. Los movimientos sociales. Madrid: Trotta, 1998, p. 173.

43 PIZZORNO, Alessandro. "Identidad e interés". En Zona Abierta, $\mathrm{N}^{\circ} 69$ (1994), p. 141.

44 MELUCCI, Alberto. "Nomads of the Present: Social Movements and Individual Needs in Contemporary Society" (1989) y "The Process of Collective Identity" (1995). Citados en TEJERINA, Benjamín. "Los movimientos sociales y la acción colectiva. De la producción simbólica al cambio de valores". En IBARRA, Pedro y Benjamín Tejerina. Los movimientos sociales. Madrid: Trotta, 1998, p. 130-132.

45 PÉREZ SILVA, Claudio. "Violencia y política en las publicaciones clandestinas bajo Pinochet. La palabra armada en el Frente Patriótico Manuel Rodríguez. Chile, 1983-1987”. En Revista de Historia Social y de las Mentalidades. 2008, N XII, Vol. 2, p. 83.

46 Campo Rebelde, $N^{o}$ 1. Periódico revolucionario clandestino dedicado a los trabajadores del campo. Enero de 1978.

47 Compañera, $N^{o} 1$. Revista de las FPL dedicada a la mujer. Mayo de 1979.

48 "Incorporémonos a las FPL". En Guerrillero (Periódico revolucionario dedicado a los estudiantes de secundaria), $\mathrm{N}^{\circ} 3$ (1979), p. 16.

49 Juventud Rebelde, $N^{o}$ 7. Periódico revolucionario de las FPL dedicado a los estudiantes universitarios. Junio de 1975.

50 Magisterio Rebelde, Año 4, $N^{o} 4$. Periódico revolucionario dedicado al maestro. Junio de 1978.

51 Magisterio Rebelde, $N^{o}$ 7. Periódico revolucionario dedicado al maestro. Junio de 1979. 
52 "El futuro pertenece a la clase obrera... ¡Impulsemos el camino combativo hacia el mañana!". En Prensa Obrera (Periódico revolucionario de las FPL dedicado a la clase obrera), Año 4, $\mathrm{N}^{\circ}$ 8 (1979), p. 9.

53 PORTA, Donatella della. "Las motivaciones individuales en las organizaciones políticas clandestinas". En IBARRA, Pedro y Benjamín Tejerina. Los movimientos sociales. Madrid: Trotta, 1998, pp. 222-223.

54 SANTULLANO, Gabriel. La prensa clandestina en Asturias. Oviedo: Fundación Juan Muñiz Zapico - KRK Ediciones, 2005, p. 109.

"Balance del primer congreso del PRS". En Publicaciones Especiales de Prensa Comunista (Octubre de 1977), pp. 3-55.

56 "Celebración exitosa del V Consejo Revolucionario de las FPL". En El Rebelde, $\mathrm{N}^{\circ} 80$ (Junio de 1979), pp. 17-23.

57 "Informe del Comando Central al Primer Consejo Revolucionario de las FPL”. En Estrella Roja, No 4 (Febrero de 1979), pp. 1-39.

58 "Vivan los comités militares". En El Combatiente, $\mathrm{N}^{\circ} 9$ (Circa abril de 1976), p. 1.

59 "Comunicado: Inician su acción los Comandos Armados Campesinos". En El Rebelde, № 12 (Octubre de 1973), p. 5 .

60 "PRS comunica sobre relaciones internacionales". En El Combatiente, $\mathrm{N}^{\circ} 9$ (Circa abril de 1976), p. 7.

61 "Informe revolucionario: Combatientes revolucionarios internacionalistas caen luchando por la liberación de Nicaragua y Centroamérica". En El Rebelde, $\mathrm{N}^{\circ}$ 81 (Julio de 1979) pp. 7, 10-12.

62 "Ex ministro de Educación se incorpora a las FPL". En El Rebelde, No 84-85 (Enero de 1989), pp. 8-9.

63 "Frente Oriental Francisco Sánchez". En El Combatiente Noviembre de 1980), pp. 20-21.

64 Algunos ejemplos en El Rebelde, $\mathrm{N}^{\circ}$ 12 (1973), 19 (1974), 43 (1976), 70 (1978).

65 Algunos ejemplos en El Rebelde, N ${ }^{\circ}$ 12 (1973), 48 (1976), 60 (1977), 72 (1978).

66 Algunos ejemplos en El Rebelde, $\mathrm{N}^{\circ}$ 27 (1975) y 66 (1978).

67 Algunos ejemplos de esta reelaboración histórica: "1971-1977, 6 años del PRSERP”. En Publicaciones Especiales de Prensa Comunista (Octubre de 1977), pp. 1-7; "9 años de guerra prolongada del pueblo". En El Rebelde, N ${ }^{\circ} 78$ (Abril de 1979), pp. 1-16.

68 "Juan Sebastián" e "Ignacio y Úrsula". En El Rebelde, $\mathrm{N}^{\circ} 46$ (Agosto de 1976), pp. 3-6.

69 "Combatientes del ERP caídos en 4 años de lucha armada". En El Combatiente, $\mathrm{N}^{\circ} 9$ (Circa abril de 1976), pp. 6-7.

70 "El pensamiento de la heroína Eva". En El Rebelde, № 54 (Abril de 1977), p. 2.

71 "Operación 'héroes revolucionarios del 11 de octubre Eva-Francisco-Antonio"'. En El Rebelde, № 55 (Mayo de 1977), pp.1-2.

72 Entrevista a Eduardo Sancho. San Salvador, 31 de octubre de 2011. 